05

\title{
Кристаллографические особенности структуры литых и закаленных сплавов кобальт-ниобий
}

\author{
(С Ю.В. Хлебникова, Л.Ю. Егорова, Т.Р. Суаридзе, Ю.Н. Акшенцев \\ Институт фризики металлов им. М.Н. Михеева УрО РАН, \\ 620108 Екатеринбург, Россия \\ e-mail: Yulia_kh@imp.uran.ru
}

Поступило в Редакцию 21 октября 2019 г.

В окончательной редакции 4 февраля 2020 г.

Принято к публикации 4 фревраля 2020 г.

Методами металлографии, сканирующей и просвечивающей электронной микроскопии, а также EBSD-анализа исследованы особенности формирования структуры при $\beta \rightarrow \alpha$ (ГЦК $\rightarrow$ ПУ)-полиморфном превращении в бинарных сплавах $\mathrm{Co}-\mathrm{Nb}$. Показано, что при постепенном охлаждении закристаллизовавшегося слитка в каждом $\beta$-зерне сплава происходит зарождение кристаллов $\alpha$-фазы нескольких ориентаций из 4 возможных в соответствии с ориентационными соотношениями Вассермана. При комнатной температуре в структуре исследованных сплавов обнаружен только $\alpha($ ПУ)-мартенсит. Разориентация субструктуры по длине мартенситных кристаллов в литых сплавах не превышает $1^{\circ}$. После гомогенизации и последующей закалки в соленой воде структура сплавов Сo- $\mathrm{Nb}$ не претерпевает морфологических и кристаллографических изменений, но заметно измельчается. При этом в несколько раз возрастает разориентация элементов субструктуры по длине мартенситных кристаллов, что является следствием высокого уровня закалочных микронапряжений в мартенсите. Каких-либо фаз с многослойными решетками типа $N R$-мартенсита не выявлено.

Ключевые слова: сплавы кобальт-ниобий, полиморфное превращение, мартенсит, ориентационные соотношения Вассермана, дифракция обратно отраженных электронов.

DOI: $10.21883 /$ JTF.2020.07.49443.344-19

\section{Введение}

Массовая доля кобальта в земной коре составляет лишь $0.004 \%$. Несмотря на такое малое количество, соединения кобальта известны человеку с глубокой древности. Синие кобальтовые стекла, эмали, краски находят при раскопках в гробницах Древнего Египта. В настоящее время кобальт и его сплавы имеют широкое практическое применение из-за высоких прочностных свойств. В кобальте и ряде бинарных кобальтовых сплавов реализуется полиморфное $\beta \leftrightarrow \alpha$ (ГЦК $\leftrightarrow$ ГПУ)-превращение, в результате которого при охлаждении высокотемпературная $\beta$-модификация с гранецентрированной кубической решеткой трансформируется в $\alpha$-фазу с гексагональной плотноупакованной решеткой $[1,2]$.

Полиморфное превращение в бинарных сплавах кобальта обладает всеми основными признаками мартенситных превращений [3-5]. Между высокотемпературной $\beta$-фазой с ГЦК-решеткой и низкотемпературной $\alpha$-фазой с ГПУ-решеткой существует строгая кристаллографическая взаимосвязь, выраженная ориентационными соотношениями Вассермана [6]:

$$
\begin{gathered}
\{111\}_{\beta} \|(0001)_{\alpha}, \\
{[10 \overline{1}]_{\beta} \|[11 \overline{2} 0]_{\alpha} .}
\end{gathered}
$$

Система $\mathrm{Co}-\mathrm{Nb}$ при комнатной температуре характеризуется наличием граничных твердых растворов на базе ОЦК-Nb при содержании до $\sim 4$ at.\% Со, ГПУ-Со при содержании до $\sim 1-2 \mathrm{at.} \% \mathrm{Nb}$ и пяти интерметаллических соединений: $\mathrm{NbCo}(\mu), \mathrm{Nb}_{9} \mathrm{Co}_{16}\left(\lambda_{1}\right), \mathrm{NbCo}_{2}\left(\lambda_{2}\right)$, $\mathrm{NbCo}_{3}\left(\lambda_{3}\right), \mathrm{Nb}_{2} \mathrm{Co}_{7}(\chi)$ [2,7]. В некоторых публикациях интерметаллидную $\mu$-фазу, имеющую в равновесном состоянии состав, близкий к эквиатомному, описывают как фазу Лавеса с составом $\mathrm{Nb}_{6} \mathrm{Co}_{7}$ [8].

В сплавах системы $\mathrm{Co}-\mathrm{Nb}$ по данным ряда исследователей, например [9], мартенситное превращение происходит аналогично превращению в чистом кобальте или кобальтовых сплавах с неограниченной растворимостью легирующего элемента, т.е. с образованием ГПУмартенсита ( $\alpha$-фазы с $2 H$ решеткой). Однако проведенные в работах $[10,11]$ исследования на монокристаллах показали, что в зависимости от содержания ниобия в сплаве наряду с $2 H$ мартенситом могут образовываться фазы $N R$ с многослойными решетками, аналогично другим бинарным кобальтовым сплавам, например, $\mathrm{Co}-\mathrm{Al}$ [12]. В сплавах, содержащих до $2 \mathrm{wt} \% \mathrm{Nb}$, образуется только ГПУ-мартенсит. При увеличении содержания легирующего элемента до 3 wt.\% в сплавах системы $\mathrm{Co}-\mathrm{Nb}$ при полиморфном превращении наряду с ГПУ-мартенситом образуется $15 \mathrm{R}_{1}$ мартенсит, при еще большей концентрации ниобия появляются политипные мартенситные структуры $126 \mathrm{R}_{1}$ и $144 \mathrm{R}_{1}$ с многослойной решеткой [11]. Возможно, что при реализации полиморфного превращения в сплавах $\mathrm{Co}-\mathrm{Nb}$ в разных термо-кинетических условиях происходит образование и 
других многослойных структур, но их кристаллические решетки пока не определены. На фазовой диаграмме политипы занимают довольно узкую концентрационную область. Для установления полной картины мартенситных превращений в системе $\mathrm{Co}-\mathrm{Nb}$ необходимо проведение дополнительных исследований.

Исходя из ориентационных соотношений Вассермана, при $\beta \rightarrow \alpha$-превращении в сплавах $\mathrm{Co}-\mathrm{Nb}$, в том случае, когда в результате превращения образуется ГПУ-мартенсит, возможно образование четырех вариантов кристаллов $\alpha$-фазы по числу плоскостей типа $\{111\}$ в ГЦК-решетке исходной $\beta$-фазы.

С развитием новых методов структурных исследований, одним из которых является метод дифракции обратно отраженных электронов (EBSD), появилась возможность уточнения ряда важных кристаллографических аспектов, касающихся характера распределения различных вариантов ориентировок мартенситной $\alpha$-фазы в объеме монокристаллов или отдельных зерен бинарных сплавов Co-Nb. Современные электронномикроскопические методы исследования тонких фольг на просвет с высоким разрешением вплоть до прямого разрешения кристаллической решетки позволяют провести кристаллографический анализ многослойных фаз, толщина прослоек которых сравнима с параметром кристаллической решетки исследуемого сплава.

Целью настоящей работы является исследование закономерностей формирования структуры в сплавах $\mathrm{Co}-2$ wt.\% $\mathrm{Nb}$ и $\mathrm{Co}-3.5$ wt.\% Nb, претерпевших $\beta \rightarrow \alpha$ (ГЦК $\rightarrow$ ГПУ) мартенситное превращение (с возможным образованием некоторой доли многослойной $N R$ мартенситной фазы) при охлаждении в разных термокинетических условиях. В работе используются металлографический, EBSD и электронномикроскопический методы анализа структуры.

\section{1. Получение образцов для исследования}

Для проведения качественного исследования кристаллографических закономерностей строения мартенсита желательно было иметь монокристаллы, так как результаты анализа, основанного на получении Кикучилиний, во многом зависят от размера структурных элементов, с которых проводится съемка. Монокристаллы сплавов $\mathrm{Co}-\mathrm{Nb}$ выращивали по методу Бриджмена в алундовых тиглях без затравки в атмосфере аргонводорода $\left(\mathrm{Ar}+4 \% \mathrm{H}_{2}\right)$ с давлением $\mathrm{P}=2 \cdot 10^{-2} \mathrm{~mm} \mathrm{Hg}$. В качестве заготовок были использованы слитки, изготовленные методом индукционной плавки из кобальта чистотой 99.98 wt.\% и ниобия марки НБШ чистотой не менее 99.8 wt.\%. Температура расплава в тигле не превышала $T_{\max }=1665^{\circ} \mathrm{C}$. Скорость кристаллизации составляла $0.95 \mathrm{~mm} / \mathrm{min}$, градиент на фронте кристаллизации - $100 \mathrm{~K} / \mathrm{cm}$. Выращенные кристаллы имели диаметр $9 \mathrm{~mm}$ и длину около $100 \mathrm{~mm}$. По данным химического анализа содержание ниобия в полученных слитках составляет 2 и 3.5 wt.\%.

Получить монокристаллы не удалось, поэтому для исследования были выбраны кристаллы с наибольшим размером зерна $-d_{\text {med }} \approx 500 \mu \mathrm{m}$.

\section{2. Методы исследования структуры}

Металлографическое исследование проводили на оптическом микроскопе „Neophot-30“. Шлифы изготавливали как в продольном, так и в поперечном сечениях кристалла. Для выявления структуры образцов использовали травление в смеси кислот $\mathrm{HNO}_{3}$ и $\mathrm{CH}_{3} \mathrm{COOH}$ в соотношении $3: 2$ с добавлением $50 \% \mathrm{H}_{2} \mathrm{O}$. Исследовали структуру сплавов $\mathrm{Co}-\mathrm{Nb}$ в исходном (литом) состоянии после гомогенизирующего отжига при температуpe $1100^{\circ} \mathrm{C}$ в течение $26 \mathrm{~h}$ и последующего охлаждения на воздухе, а также после гомогенизирующего отжига с последующей закалкой в 10\%-ном водном растворе $\mathrm{HCl}$. Средний размер зерна в сплавах оценивали по металлографическим шлифам методом секущих.

Ориентацию $\alpha$-фазы в различных сечениях и зернах сплавов определяли методом дифракции обратно отраженных электронов (EBSD), заключающимся в расшифровке картин Кикучи-линий с помощью специализированной приставки фирмы EDAX к сканирующему электронному микроскопу FEI „Quanta-200“. Образцы для EBSD-анализа вырезали в виде шайб толщиной около $2 \mathrm{~mm}$. Диаметр пучка при формировании дифракционной картины составлял около $50 \mathrm{~nm}$, шаг сканирования 50 или $100 \mathrm{~nm}$. Образцы перед съемкой подвергали электролитической полировке. Для оценки разориентации структурных элементов строили профили вдоль выбранных направлений. Профили разориентации по длине кристаллов $\alpha$-фазы строили в режиме „роint-to-origin“, позволяющем сравнивать последовательно ориентацию каждой просканированной точки с исходной, а разориетацию разных областей $\alpha$-фазы - в режиме ,pointto-point“, чтобы оценить изменение ориентации при пересечении границы соседствующих $\alpha$-областей.

Электронно-микроскопическое исследование осуществляли на сканирующих электронных микроскопах Phenom XL и FEI „Quanta-200“.

\section{3. Результаты эксперимента и их обсуждение}

В сплавах системы $\mathrm{Co}-\mathrm{Nb}$ полиморфное превращение реализуется в очень узком концентрационном диапазоне при содержании ниобия не более $7 \mathrm{wt} . \%$; при большем содержании ниобия в сплаве происходит стабилизация высокотемпературной $\beta$-фазы. Следует учесть также, что указанное значение предельного содержания ниобия соответствует температуре $-200^{\circ} \mathrm{C}$. Когда охлаждение литого сплава проводят на воздухе, при достижении 

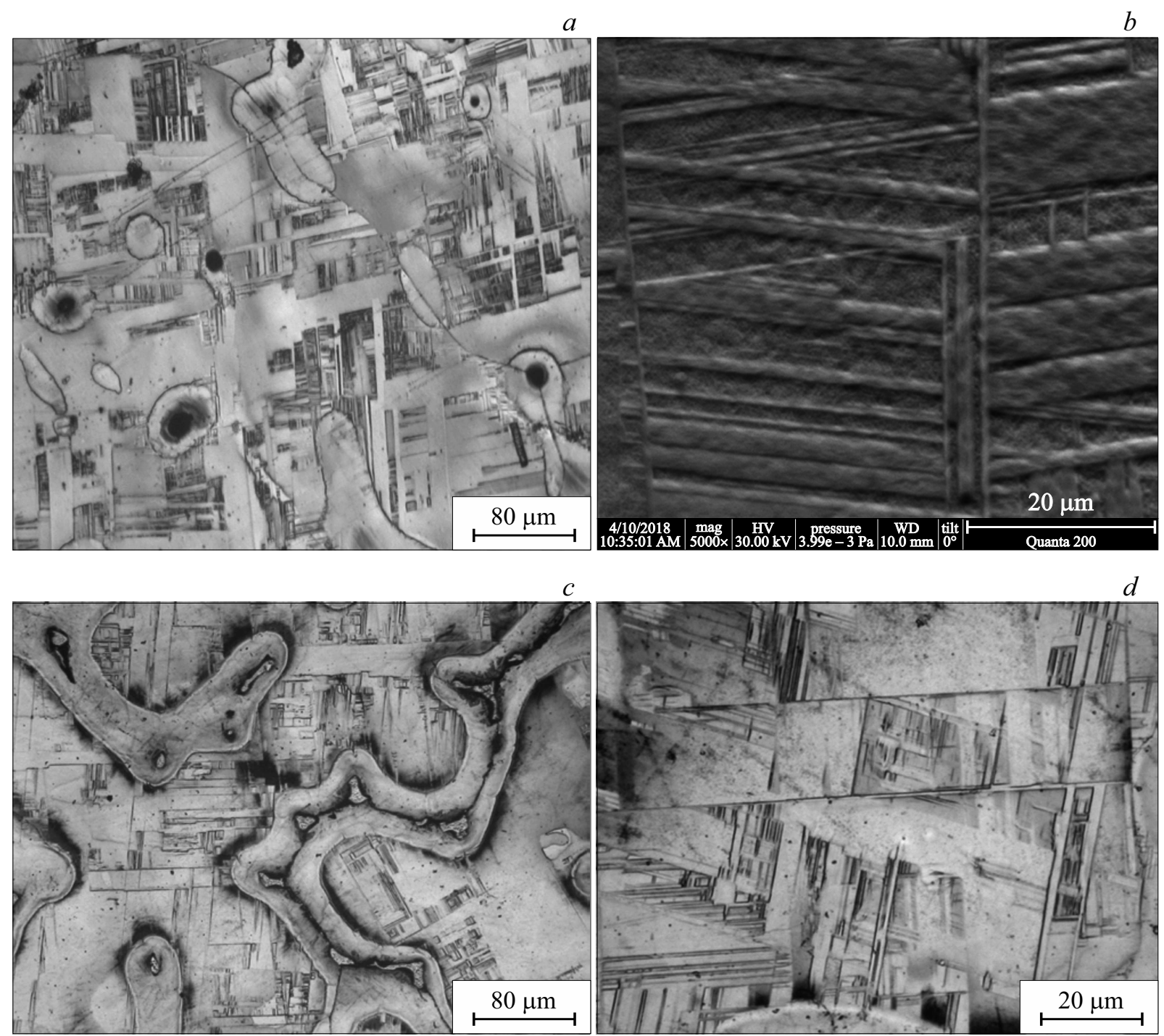

Рис. 1. Микроструктура литых сплавов Сo-2 wt.\% $\mathrm{Nb}(a, b)$ и Сo- $3.5 \mathrm{wt} . \% \mathrm{Nb}(c, d): a, c-$ структурная неоднородность; $b, d-$ пластины мартенсита в областях реализации полиморфного превращения.

комнатной температуры полиморфное превращение реализуется только в тех участках сплава, где содержание ниобия не выше 4 wt.\%.

Исследуемые сплавы $\mathrm{Co}-2 \mathrm{wt} . \% \quad \mathrm{Nb} \quad$ и Co-3.5 wt.\% $\mathrm{Nb}$ представляли собой крупнокристаллические поликристаллы со средним размером зерна около $500 \mu \mathrm{m}$. Такой крупнозернистый поликристалл является удобным объектом для проведения EBSDанализа кристаллографических ориентаций мартенсита, так как размер мартенситных кристаллов, образующихся в результате полиморфного $\beta \rightarrow \alpha$-превращения, коррелирует с размером зерна.

\section{1. Структура сплава Co-2 wt.\% Nb в литом состоянии}

Полиморфное $\beta \rightarrow \alpha$-превращение реализовалось не во всем объеме сплава. На металлографических шлифах присутствуют области неправильной формы, в которых не прошло превращение (рис. 1,a). В тех участках, где превращение прошло, присутствуют пластины мартенсита нескольких кристаллографических ориентаций (рис. 1,b).

Известно, что превращение в бинарных кобальтовых сплавах, как и в чистом кобальте, не проходит полностью, в структуре всегда сохраняется некоторое количество остаточной высокотемпературной $\beta$-фазы. По мере увеличения содержания легирующего элемента температура $\beta \leftrightarrow \alpha$-превращения в кобальте и бинарных сплавах кобальта понижается вплоть до температуры жидкого азота с одновременным уменьшением количества образующейся $\alpha$-фазы $[3,13,14]$. Микроструктура $\alpha$-фазы в бинарных сплавах $\mathrm{Co}-\mathrm{Nb}$, как и в чистом кобальте, имеет пластинчатую морфологию, а остаточная $\beta$-фаза также имеет форму пластин, чередующихся с пластинами $\alpha$-фазы. Разница состоит в том, что пластины $\alpha$-фазы 

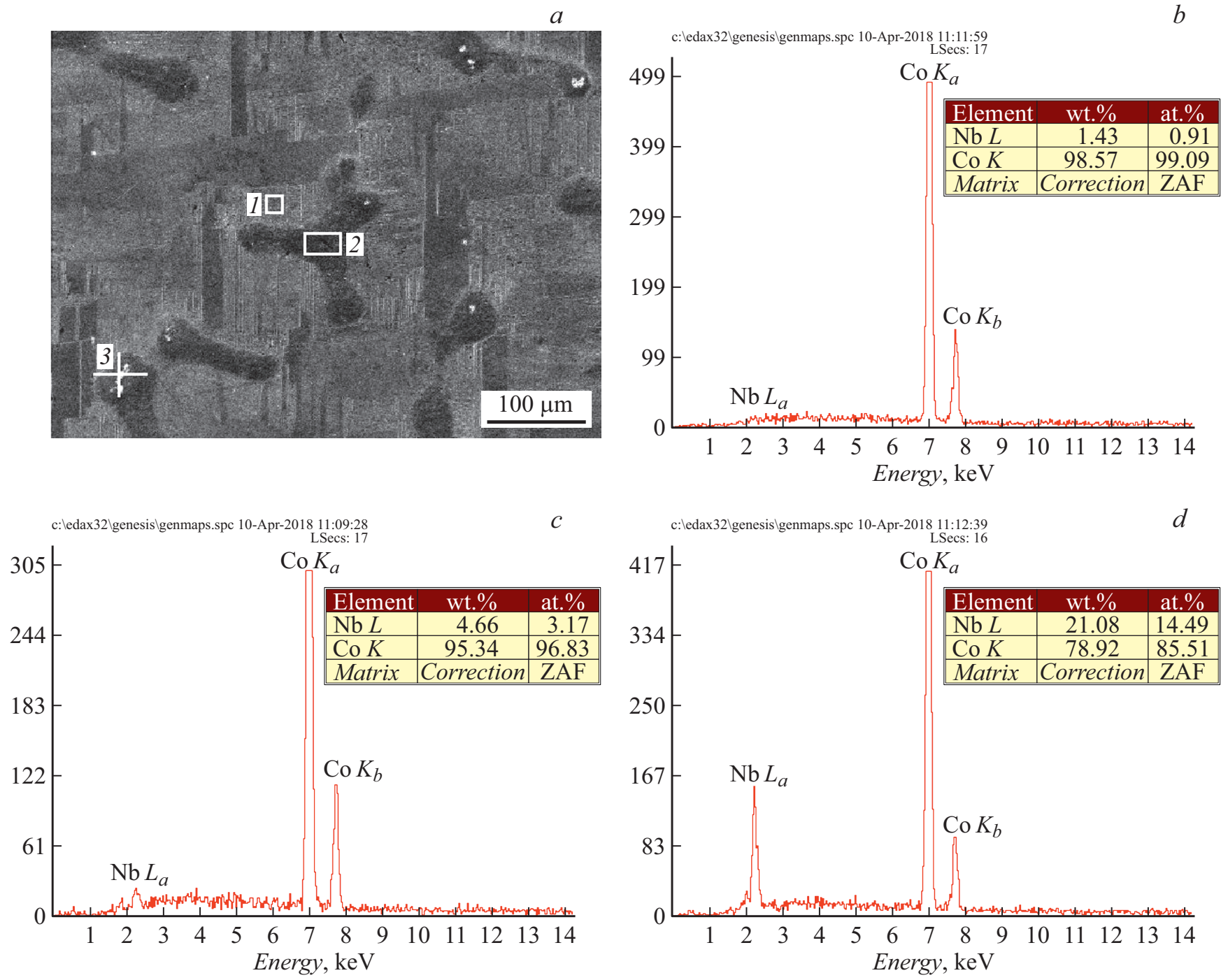

Рис. 2. Результаты химического анализа литого сплава Сo- $2 \mathrm{wt} . \% \mathrm{Nb}: a-$ участок структуры с выделенными участками рентгеноспектрального микроанализа; $b-$ спектр с участка реализации мартенситного превращения; $c-$ спектр с междендритного пространства, где фазовый переход не реализовался; $d$ - спектр с частицы интерметаллида.

состоят из набора тонких пластинок, в то время как пластины $\beta$-фазы имеют однородное строение [3].

По форме области, где превращение реализовалось, представляют собой сечения осей дендритов под большим углом, а области остаточной $\beta$-фазы располагаются в междендритных пространствах. Конечно, остаточная $\beta$-фаза в виде тонких прослоек между мартенситными пластинами должна присутствовать и в тех областях, где прошло $\beta \rightarrow \alpha$-превращение, но при металлографическом анализе эти тонкие прослойки не удается отличить от мартенсита. Такое распределение структурных составляющих в образце связано с существенной неоднородностью по химическому составу. В процессе кристаллизации оси дендритов содержат заметно меньше ниобия, чем его среднее содержание в сплаве. В свою очередь, междендритные пространства, закристаллизовавшиеся в последнюю очередь, содержат большее ко- личество ниобия, чем предельно допустимое значение для образования $\alpha$-фазы при охлаждении сплава до комнатной температуры. Поэтому на металлографических шлифах присутствуют области непревращенной $\beta$-фазы, зачастую образующие конфигурации, окаймляющие тройной стык зерен, хотя границы бывших дендритов не всегда совпадают с границами зерен.

Иногда в непревращенных областях обнаруживаются дисперсные частички неправильной формы (рис. 2). Такие частицы располагаются обычно в тройных стыках зерен (рис. 2,a). Как показал локальный энергодисперсионный химический анализ, в областях реализации мартенситного превращения содержание ниобия составляет около 1.5 wt. $(\sim 1$ at.)\% (рис. $2, b)$, а в бывших междендритных пространствах - чуть более $4.5 \mathrm{wt}$. ( 3 at.)\% (рис. $2, b)$. Частицы содержат около 15 at.\% ниобия и 85 at.\% кобальта, т. е. состав выделившихся ча- 

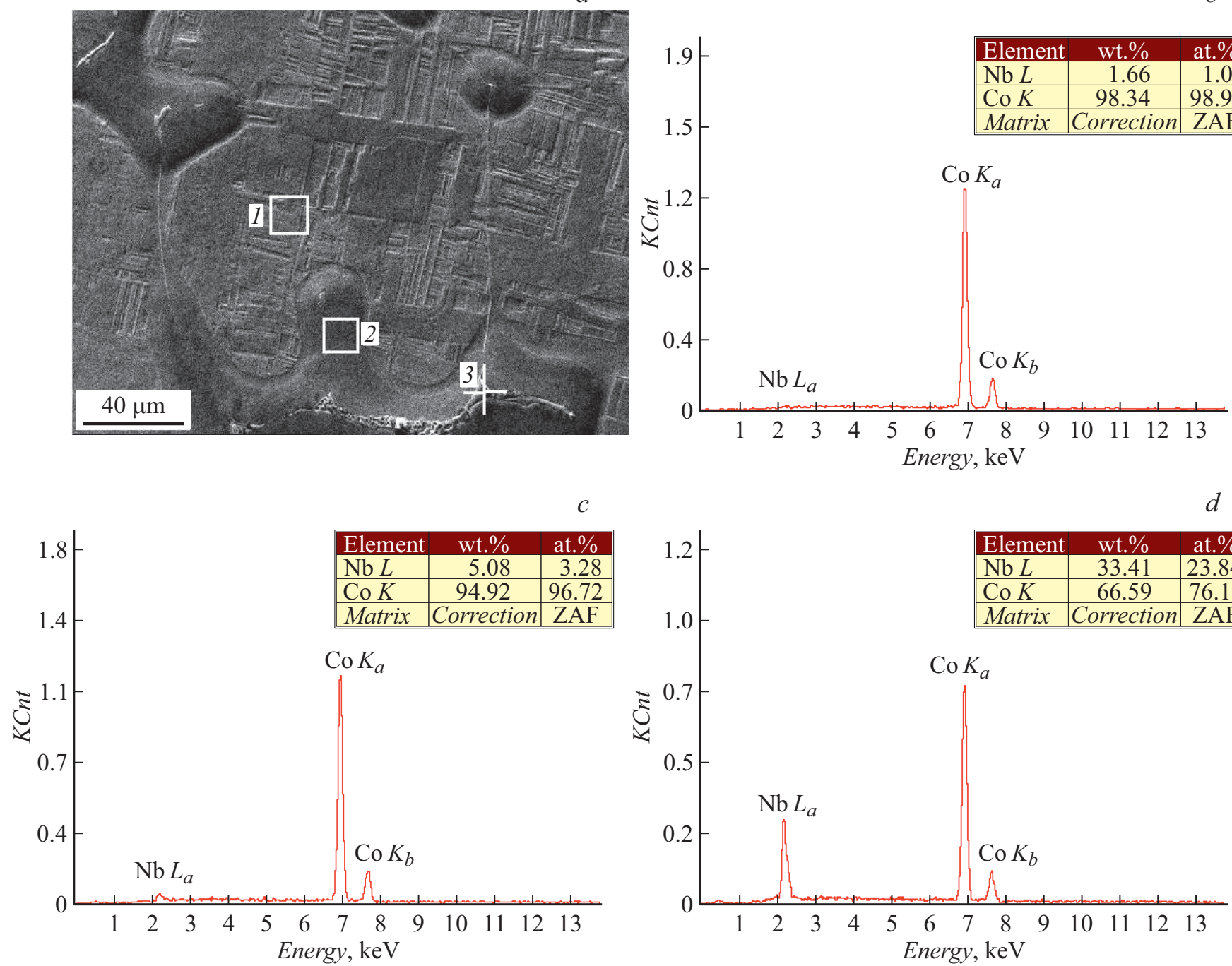

Рис. 3. Результаты химического анализа литого сплава Co-3.5 wt.\% Nb: $a$ - участок структуры с выделенными участками рентгеноспектрального микроанализа; $b-$ спектр с участка реализации мартенситного превращения; $c$ - спектр с междендритных пространств, где фазовый переход не реализовался; $d-$ спектр с частицы интерметаллида.

стиц близок к составу интерметаллидной фазы $\mathrm{Co}_{7} \mathrm{Nb}_{2}$. Учитывая попадание некоторого количества матричной фазы в выбираемый участок при съемке элементного спектра с частицы, значение второй фазы несколько ниже соответствующего стехиометрическому составу (рис. $2, d$ ). Это первый со стороны кобальта интерметаллид ( $\chi$-фаза) с наименьшим содержанием ниобия в ряду интерметаллидных фаз, образующихся в системе $\mathrm{Co}-\mathrm{Nb}[8]$.

\section{2. Структура сплава Сo-3.5 wt.\% Nb в литом состоянии}

Качественной разницы в структуре сплавов с 2 и $3.5 \mathrm{wt} . \% \mathrm{Nb}$ при металлографическом анализе не выявлено. Однако заметно, что с увеличением содержания ниобия в сплаве увеличивается доля площади, не занятая превращением, а также, что количество интерметаллидных частиц в непревращенных областях значительно больше, к тому же они крупнее (рис. 1,c). Количественные различия в фазовом составе сплавов закономерны, поскольку в сплаве с меньшим содержанием ниобия расслоение по химическому составу выражено в меньшей степени, чем в сплаве с $3.5 \%$ ниобия. Мартенсит имеет такую же пластинчатую морфологию и несколько кристаллографических ориентаций (рис. $1, d$ ).

Результаты химического анализа различных участков структуры литого сплава $\mathrm{Co}-3.5 \mathrm{wt} \% \mathrm{Nb}$ представлен на рис. 3. Частицы в этом сплаве в основном образуют скопления, вытянутые вдоль границ зерен (рис. 3, $a$ ). В спектре с участка реализации мартенситного превращения регистрируется, как и в первом сплаве, около 1.5 wt. ( 1 at.)\% ниобия (рис. $3, b)$, в то время как в междендритных пространствах, где фазовый переход не реализовался, содержание ниобия составляет более $5 \mathrm{wt}$. 


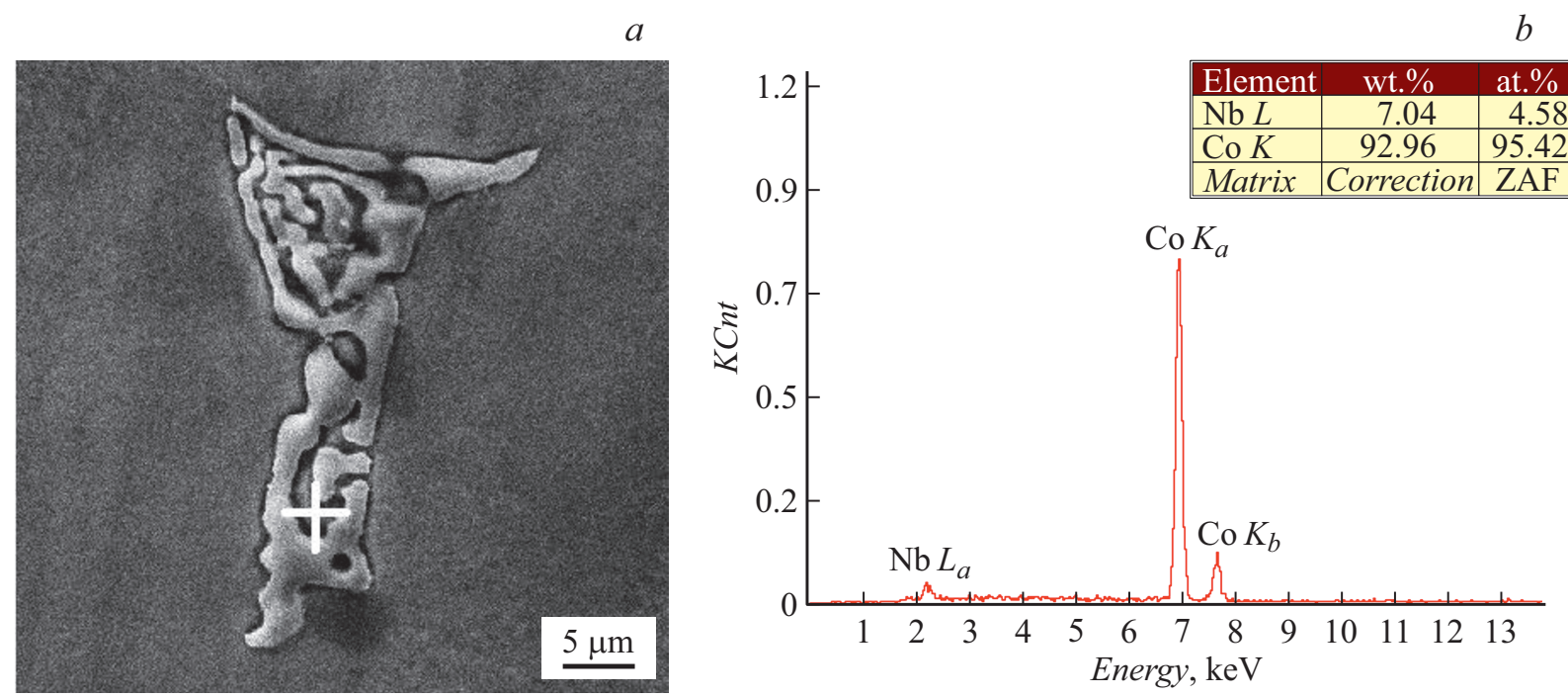

Рис. 4. Результаты химического анализа интерметаллидного конгломерата в литом сплаве Co-3.5 wt.\% Nb: $a-$ микроструктура; $b$ - спектр с островка непревращенной $\beta$-фазы между интерметаллидными частицами.

(более 3 at.)\% (рис. 3,c). Энергодисперсионный химический анализ выявил существенную разницу в составе интерметаллидных частиц - около 24 at.\% ниобия и 76 at.\% кобальта, т.е. состав выделившихся частиц с незначительными отклонениями соответствует составу другой интерметаллидной фазы $\mathrm{Co}_{3} \mathrm{Nb}$ (рис. 3,d). Этот интерметаллид в соответствии с фазовой диаграммой $\mathrm{Co}-\mathrm{Nb}$ стоит вторым со стороны кобальта ( $\lambda_{3}$-фаза) в ряду известных интерметаллидных фаз [2,7]. Однако согласно равновесной диаграмме состояния, эта фаза существует только в ограниченном температурном интервале от $\sim 1000$ до $1240^{\circ} \mathrm{C}$, а при охлаждении до более низких температур происходит реакция $\mathrm{Co}_{3} \mathrm{Nb}$ $\rightleftarrows \mathrm{Co}_{2} \mathrm{Nb}+\mathrm{Co}_{7} \mathrm{Nb}_{2}$. Следовательно, при комнатной температуре в структуре должны присутствовать два разных по составу интерметаллида: $\mathrm{Co}_{2} \mathrm{Nb}$ и $\mathrm{Co}_{7} \mathrm{Nb}_{2}$. При более детальном рассмотрении выделившихся в бывших междендритных пространствах литого сплава Co-3.5 wt.\% Nb интерметаллидных частиц выяснилось, что они заметно различаются по морфологии и размеру. Более мелкие частицы имеют либо форму, близкую к сферической, либо достаточно четкую кристаллографическую огранку. Более крупные выделения представляют собой не отдельные частицы, а конгломерат частиц сложной формы, разделенных островками непревращенной $\beta$-фазы (рис. 4,a). В пределах конгломерата $\beta$-фаза содержит заметно большее количество ниобия (около 7 wt. или 4.5 at.\%), чем $\beta$-фаза, окружающая этот конгломерат (рис. 4, $b$ ). При этом сами частицы содержат около 33 at.\% ниобия и 67 at.\% кобальта, что соответствует составу интерметаллида $\mathrm{Co}_{2} \mathrm{Nb}$. При съемке рентгеновских спектров с мелких частиц оказалось, что их химический состав отвечает составу интерметаллида $\mathrm{Co}_{7} \mathrm{Nb}_{2}$, как и в сплаве $\mathrm{Co}-2$ wt.\% Nb. Следовательно, в структуре литого сплава Co-3.5 wt.\% Nb присутствуют два типа интерметаллидных частиц разного состава и морфологии.

\section{3. Структура сплавов $\mathrm{Co}-\mathrm{Nb}$ после гомогенизации}

После проведения гомогенизирующего отжига, предпринятого с целью устранения расслоения по химическому составу, анализировали возможное изменение морфологии и структуры мартенсита, а также изменения количества и химического состава интерметаллидных включений. В сплаве, содержащем 2 wt.\% $\mathrm{Nb}$, отжиг привел к выравниванию химического состава, в результате чего мартенситное превращение реализовалась во всем объеме. При этом морфология мартенсита не изменилась, а также не произошло выделения интерметаллидов, по крайней мере таких, которые можно было бы наблюдать при металлографическом анализе.

В сплаве с бо́льшим содержанием ниобия гомогенизирующий отжиг не привел к полному выравниванию химического состава, однако доля участков, в которых мартенситное превращение не реализовалось, значительно уменьшилась. При этом также уменьшилось количество выделившихся интерметаллидов и их размер, а участков, содержащих конгломераты частиц неправильной формы, обнаружено не было. Следует отметить, что все проанализированные частицы в гомогенизированном сплаве $\mathrm{Co}-3.5$ wt.\% $\mathrm{Nb}$ имели состав $\mathrm{Co}_{7} \mathrm{Nb}_{2}$. Частиц, соответствующих составу интерметаллида $\mathrm{Co}_{2} \mathrm{Nb}$, не выявлено. Морфология мартенсита, как и в первом сплаве, не изменилась.

\section{4. Структура сплавов Co-Nb после закалки}

Морфологически структура сплавов после закалки не претерпела заметных изменений, по крайней мере, 


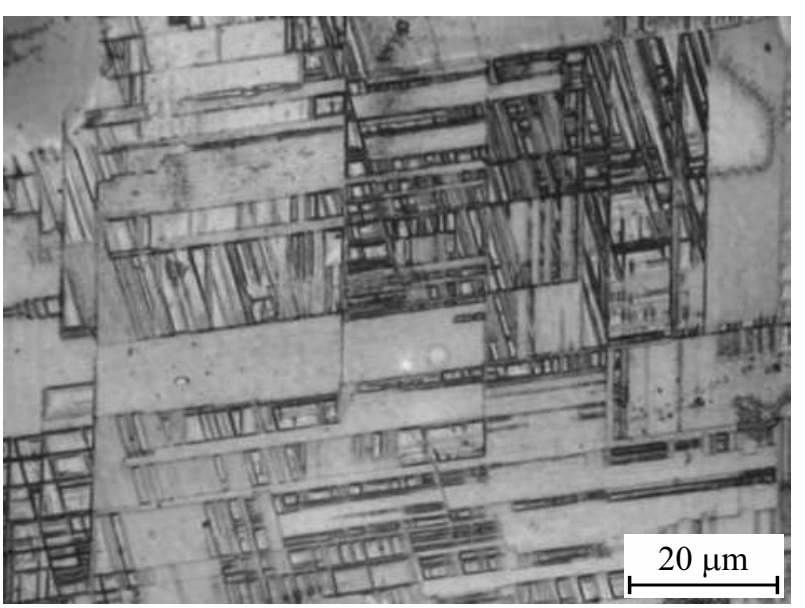

Рис. 5. Микроструктура гомогенизированного и закаленного сплава $\mathrm{Co}-2$ wt.\% $\mathrm{Nb}$.

металлографически (рис. 5). Можно отметить заметное измельчение пластин мартенсита - уменьшение как их протяженности, так и ширины. Аналогичное измельчение кристаллов мартенсита ранее наблюдали в чистом кобальте при исследовании закономерностей $\beta \rightarrow \alpha$-превращения при увеличении скорости охлаждения [15]. Протяженность пластин по металлографической оценке уменьшается в 2-3 раза. Говорить об изменении толщины пластин сложно, учитывая, что визуально наблюдаемая пластина представляет собой не монолит, а набор параллельных пластинок одной ориентации.

\subsection{EBSD-анализ литых сплавов Co-Nb}

Для проведения EBSD-анализа выбирали такие участки образца, где реализовалось $\beta \rightarrow \alpha$-полиморфное превращение. Желательно также, чтобы выбранная область не содержала границ зерен. Исходя из реализации ориентационных соотношений, при $\beta \rightarrow \alpha$ - превращении в сплавах $\mathrm{Co}-\mathrm{Nb}$, в том случае, когда в результате превращения образуется ГПУ-мартенсит, возможно образование четырех вариантов кристаллов $\alpha$-фазы по числу плоскостей типа $\{111\}$ в ГЦК-решетке исходной $\beta$-фазы.

В бинарных сплавах кобальта, как и в чистом кобальте, при комнатной температуре сохраняется некоторое количество остаточной $\beta$-фазы между пластинами гексагонального мартенсита. Поэтому сначала осуществляли фазовый анализ структуры сплавов и при съемке ориентационных EBSD-микрокарт задавали параметры решетки ГПУ-мартенсита и $\beta$-фазы. При фазовом EBSDанализе, результаты которого представлены на рис. 6, выявлено, что прослойки $\beta$-фазы в структуре литого сплава Co- 3.5 wt.\% $\mathrm{Nb}$ присутствуют в достаточно большом количестве (соотношение фаз примерно равное). Однако можно провести только качественную оценку фазового состава, поскольку большую роль играет угол наклона мартенситных пластин к плоскости, с которой производится съемка микрокарт, а также крайне малая толщина пластин мартенсита и остаточной $\beta$-фазы, затрудняющие проведение корректной оценки количества фаз при относительно небольших увеличениях микроскопа, используемых при EBSD-анализе.

В случае присутствия в структуре кроме ГПУ-мартенсита каких-либо многослойных мартенситных фаз с другими параметрами кристаллической решетки, на ориентационной микрокарте должны быть „непрочитанные“ области, т.е. участки, в которых не удалось определить ориентацию, исходя из параметров решетки $\alpha$-мартенсита. Из общего числа проанализированный точек на ориентационной микрокарте (рис. 6, число точек, в которых не удалось определить ориентацию составляет около $0.1 \%$ (Number of points - 58674; Number of good points - 58609), следовательно, каких-либо фаз, кроме $\alpha$ - и $\beta$, в сплаве не образовалось. Более детально распределение остаточной $\beta$-фазы между пластинами мартенсита анализировали методом просвечивающей электронной микроскопии.

На рис. 7 представлена ориентационная микрокарта с области реализации мартенситного превращения в сплаве $\mathrm{Co}-3.5$ wt.\% $\mathrm{Nb}$, не содержащей границ зерна. Известно, что в ГЦК кристаллической решетке $\beta$-фазы угол между плоскостями типа $\{111\}$, входящими в ориентационные соотношения Вассермана, составляет $71 \mathrm{deg}$. Соответственно на полюсной фигуре гексагональной $\alpha$-фазы исследуемых сплавов $\mathrm{Co}-\mathrm{Nb}$ при комнатной температуре между полюсами (0001) должно быть такое же угловое расстояние, при условии, что эти ориентировки реализовались из одного $\beta$-зерна.

Положения нормалей от структурных элементов анализируемой области в стандартном стереографическом треугольнике не совпадают для разных ориентаций кристаллов (рис. 7,b). На экспериментальной полюсной фигуре присутствуют текстурные максимумы от четыpex различных ориентаций $\alpha$-фазы (рис. 7,c). Каждый текстурный максимум на полюсной фигуре был идентифицирован и пронумерован в соответствии с EBSD ориентационной микрокартой на рис. 7,a. Угловые расстояния между различными текстурными максимумами соответствуют $\sim 71 \mathrm{deg}$, т.е. все кристаллы $\alpha$-фазы образовались из одного исходного $\beta$-зерна. Для более точного определения угловой разориентации кристаллов $\alpha$-фазы строили профили разориентации вдоль линий, отмеченных на рис. 7, $a$.

Разориентировка вдоль линии $A B$ при переходе от кристалла с ориентацией III к кристаллу с ориентацией II составляет около $71 \mathrm{deg}$ (рис. 8,a). При пересечении всех других границ вдоль линии $A B$ ориентация также скачкообразно меняется на $71 \mathrm{deg}$. Интересная ситуация складывается при анализе изменения ориентации структурных элементов вдоль линии $C D$ (рис. $8, b)$. На линии имеются три плато, обозначенные как 1,2 и 3, которые соответствуют разным кристаллам мартенсита, имеющим одинаковую ориентацию III. Видно, что 

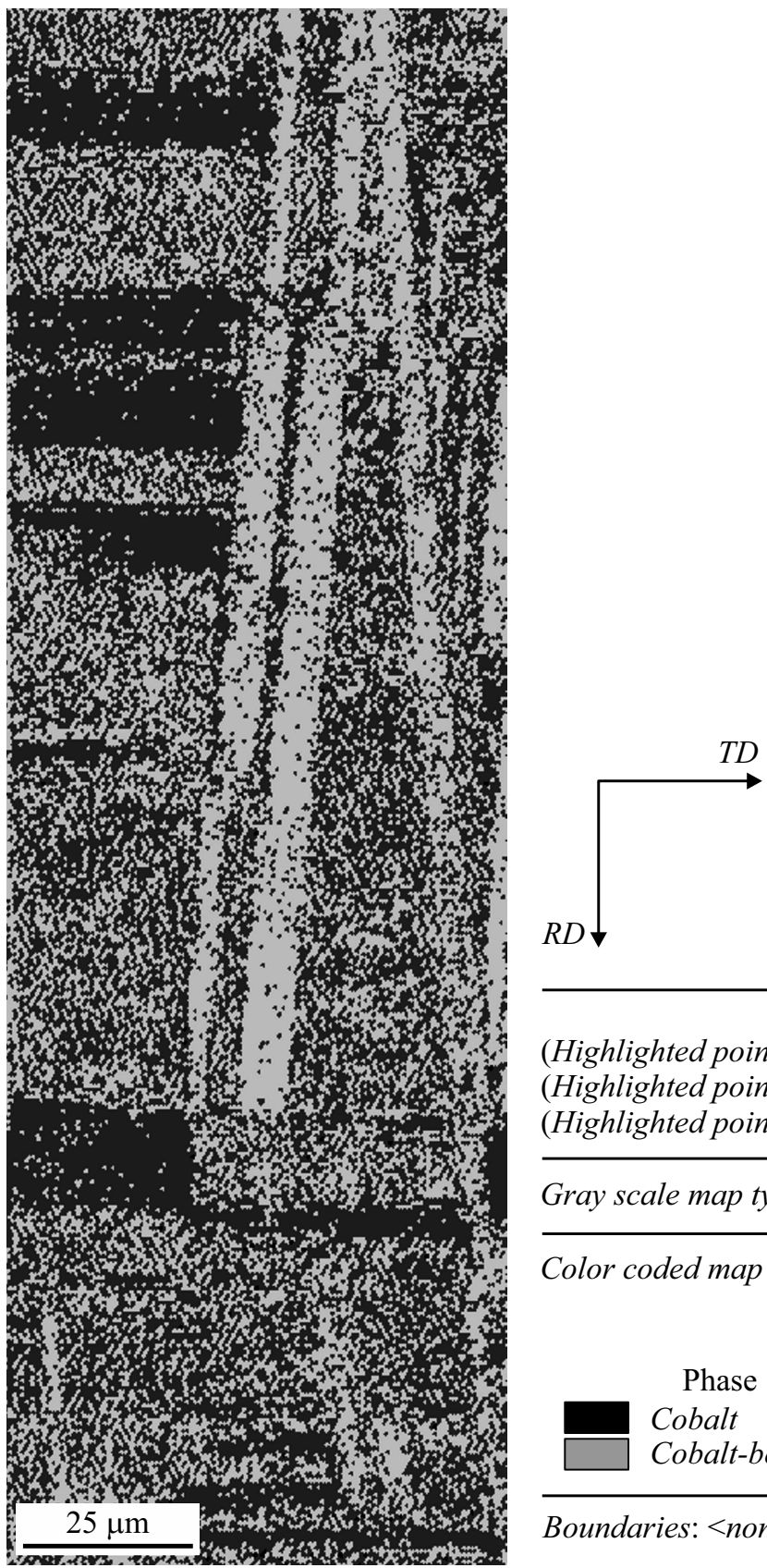

(Highlighted points $) /($ Total number of points $)=0.000$ (Highlighted points $) /($ Number of good points $)=0.000$ (Highlighted points)/(Number of partition points $)=0.000$

Gray scale map type: <none $>$

Color coded map type: phase

\begin{tabular}{|ccc} 
Phase & $\begin{array}{c}\text { Total } \\
\text { fraction }\end{array}$ & $\begin{array}{c}\text { Partition } \\
\text { fraction }\end{array}$ \\
Cobalt & 0.557 & 0.557 \\
Cobalt-beta & 0.442 & 0.442
\end{tabular}

Boundaries: <none $>$

Pис. 6. Качественная оценка фазового состава литого сплава Co-3.5 wt.\% Nb методом EBSD.

исходная точка сканирования, также как и конечная, разориентированы относительно этих плато на угол $71^{\circ}$. При этом в участках между плато, соответствующих ориентации мартенсита IV, присутствуют периодические скачкообразные изменения ориентации на углы более $90^{\circ}$. По-видимому, это связано с малой толщиной пластинок мартенсита ориентации IV, чередующихся с тонкими пластинками остаточной $\beta$-фазы.

Элементы субструктуры в пределах одной ориентировки $\alpha$-фазы слабо разориентированы, о чем свидетельствует высокая плотность текстурных максимумов I-III на полюсной фигуре (рис. 7, c). Наименьшую текстурную плотность демонстрирует максимум, соответствующий ориентации кристаллов IV. По-видимому, петлеобразное размытие именно этого текстурного максимума связано с малой толщиной пластинок мартенсита ориентации IV. Например, профиль разориентации вдоль линии $E K$ по длине $\alpha$-кристалла ориентировки II демонстрирует разориентировку в пределах $1 \mathrm{deg}$ (рис. 8,c). По длине еще нескольких проанализированных кристаллов $\alpha$-фазы (например, на участке линии $A B$ в кристалле мартенсита ориентации III до скачкообразного изменения ориентировки при пресечении границы) разориентировка также не превышает $1 \mathrm{deg}$. 

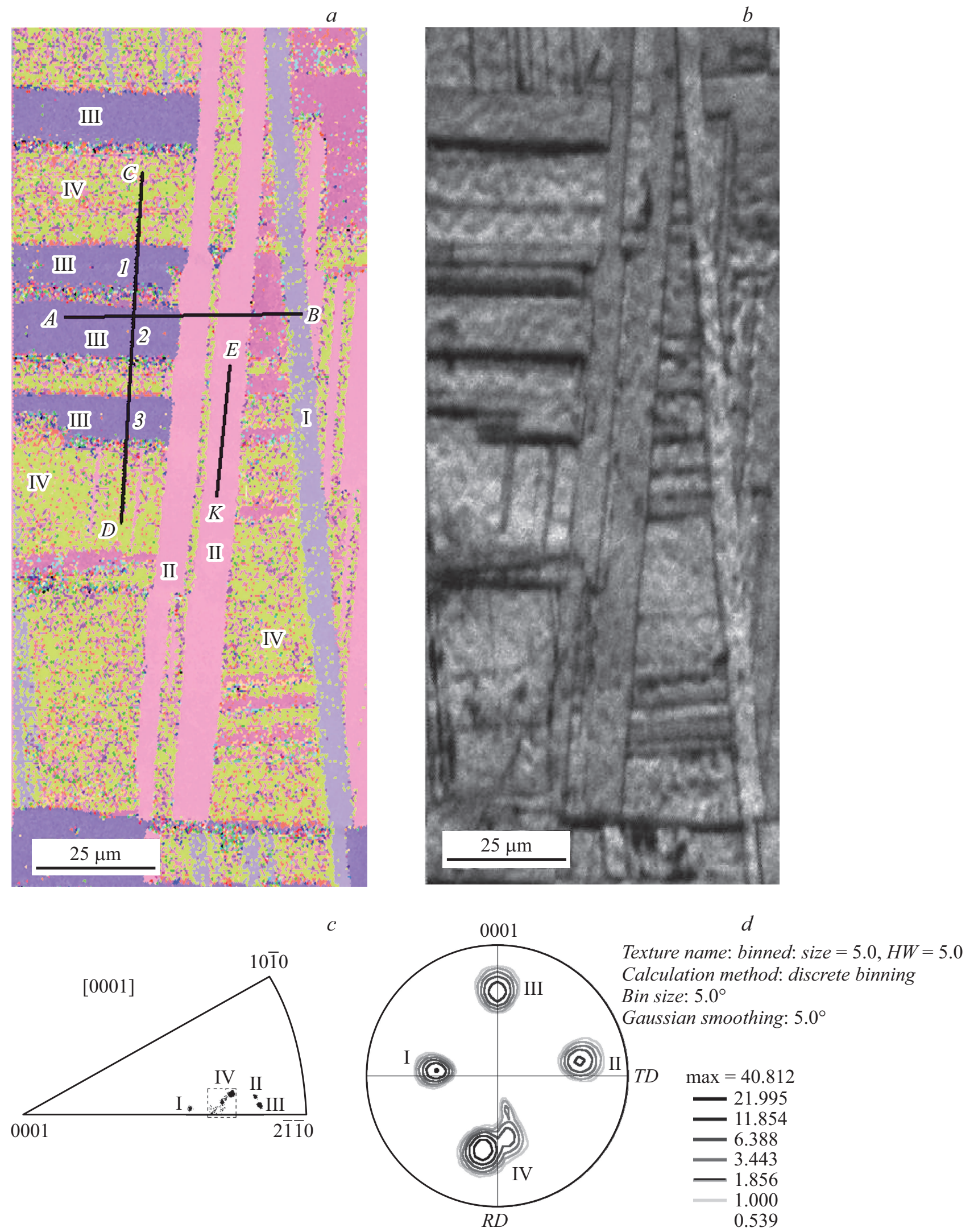

Рис. 7. Результаты EBSD-анализа литого сплава Co-3.5 wt.\% Nb: $a$ - ориентационная микрокарта; $b$ - изображение структуры, восстановленное по линиям Кикучи; $c$ - положения нормалей [0001] к базисным плоскостям мартенсита в стандартном стереографическом треугольнике; $d-$ полюсная фигура (0001) и уровни плотности текстурных максимумов. 

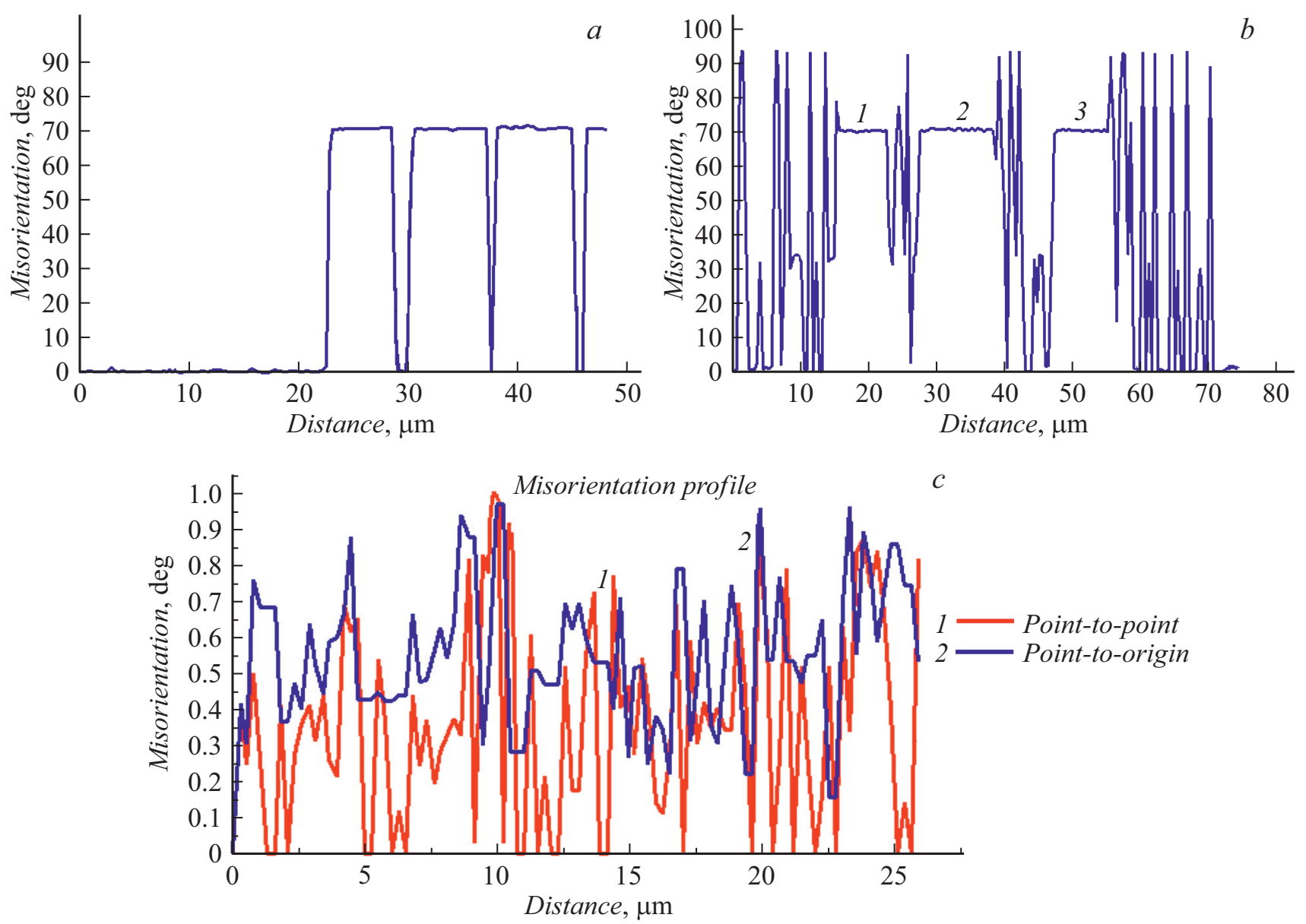

Рис. 8. Профили разориентации структурных элементов вдоль выбранных направлений в соответствии с рис. 7, $a$ : $a-A B$, $b-C D, c-E K$.

Все другие проанализированные места содержали либо такой же набор кристаллографических ориентировок $\alpha$-фазы, либо 2-3 ориентировки из четырех возможных, исходя из реализации ориентационных соотношений Вассермана.

В сплаве Co-2wt.\% Nb наблюдается аналогичная картина с точки зрения количества и характера распределения в объеме зерна различных ориентаций $\alpha$-фазы. Однако при проведении фазового анализа было обнаружено, что количество остаточной $\beta$-фазы существенно меньше (менее 20\%). Такой результат вполне закономерен и согласуется с литературными данными о том, что в бинарных кобальтовых сплавах с ограниченной растворимостью с увеличением содержания легирующего элемента полнота превращения снижается и соответственно доля сохранившейся высокотемпературной фазы в конечной структуре возрастает [3].

\subsection{EBSD-анализ гомогенизированных и закаленных сплавов Co-Nb}

При выборе анализируемого участка старались, так же как и для литых сплавов, избегать границы зерен. Кроме того, выбирали места, содержащие кристаллы нескольких направлений. В качестве примера на рис. 9 представлены результаты EBSD-анализа закаленного сплава Co-3.5 wt.\% Nb. Участок на ориентационной микрокарте рис. 9, $a$ морфологически подобен участку структуры литого сплава на рис. 7, $a$, но степень дисперсности структуры выше в несколько раз.

На полюсных фигурах угловые расстояния между полюсами (0001) не изменились, но уровень текстурной плотности снизился для обоих сплавов по сравнению с литым состоянием (рис. 9,b). Снижение уровня текстурной плотности может свидетельствовать об увеличении разориентации элементов субструктуры по длине кристаллов мартенсита. Действительно, профиль линии $M N$ при сканировании в режиме „point-to-origin“ демонстрирует постепенное нарастание разориентации, и на расстоянии $25 \mu \mathrm{m}$ от начальной точки сканирования разориентировка составляет уже более $3 \mathrm{deg}$ (рис. 9,c). Этот факт можно объяснить более высоким уровнем остаточных микронапряжений в закаленной структуре, вызывающих искривление кристаллов мартенсита. 


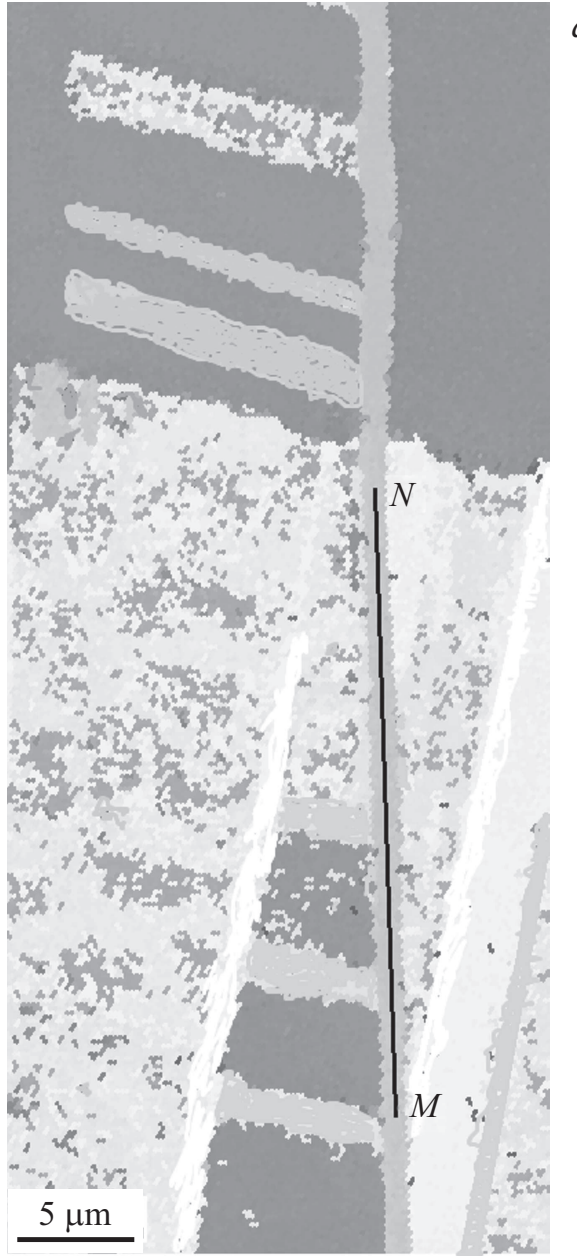

$c$

Texture name: binned: size $=5.0, H W=5.0$ Calculation method: discrete binning Bin size: $5.0^{\circ}$

Gaussian smoothing: $5.0^{\circ}$

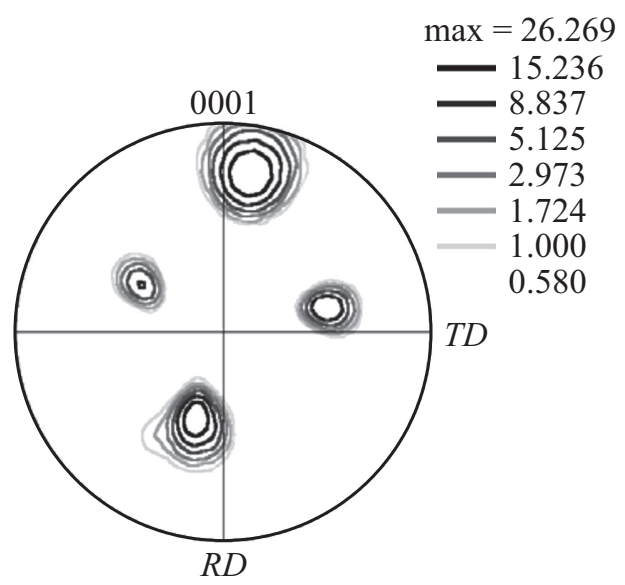

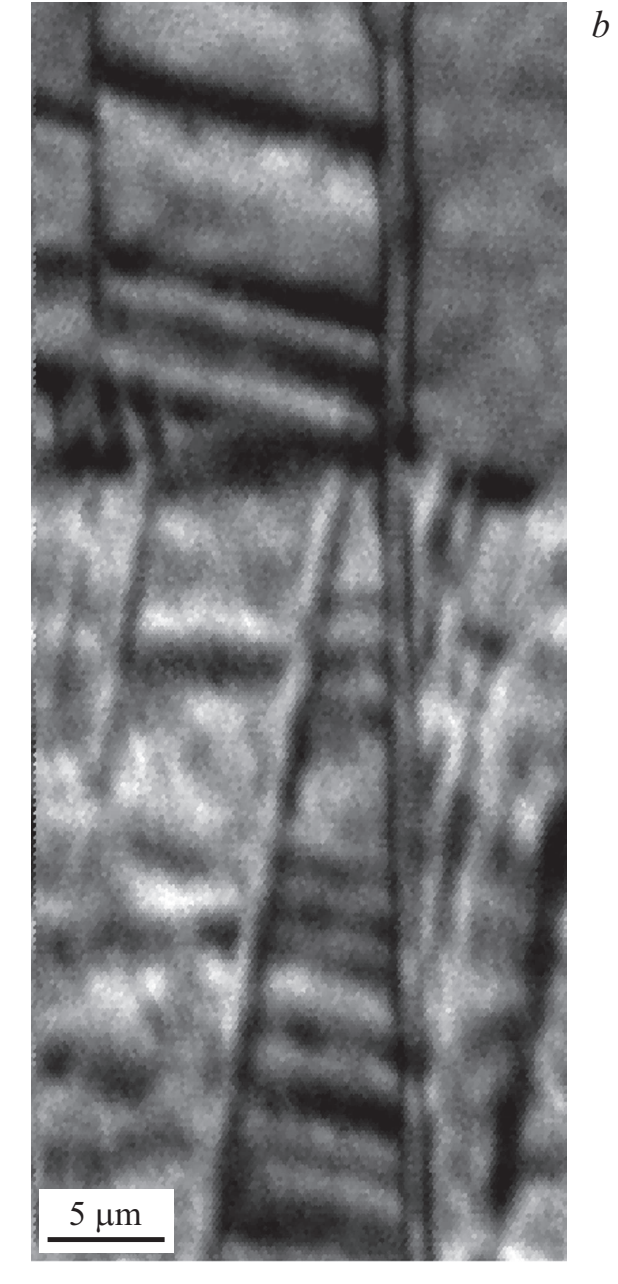

$b$

$d$

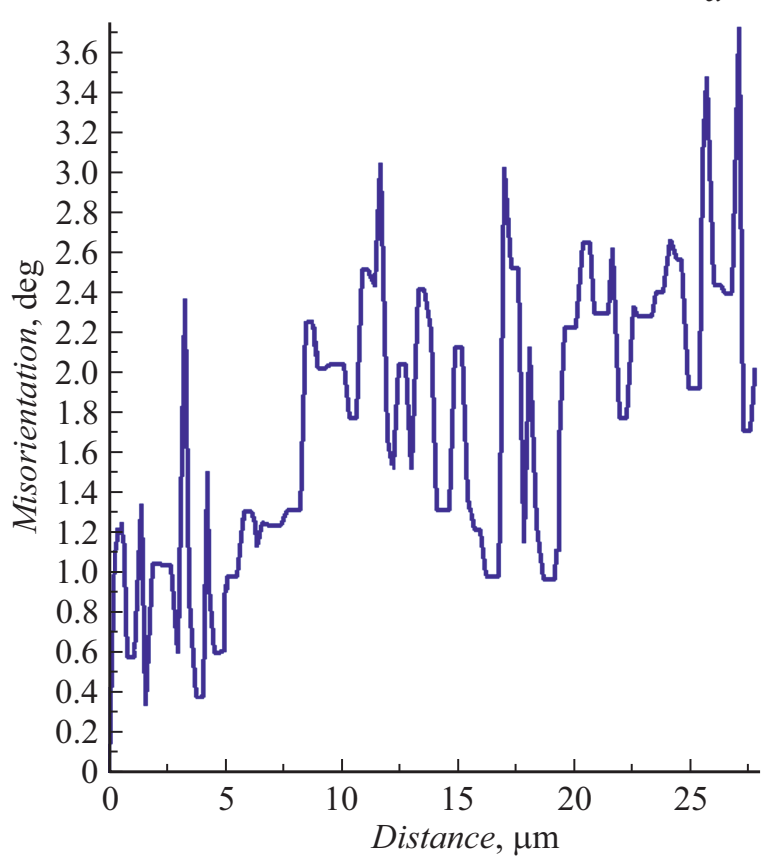

Рис. 9. Результаты EBSD-анализа сплава Co-3.5 wt.\% Nb после гомогенизации и закалки: $a$ - ориентационная микрокарта; $b-$ изображение структуры, восстановленное по линиям Кикучи; $c-$ полюсная фигура (0001) и уровни плотности текстурных максимумов; $d-$ профиль разориентации вдоль линии $M N$. 

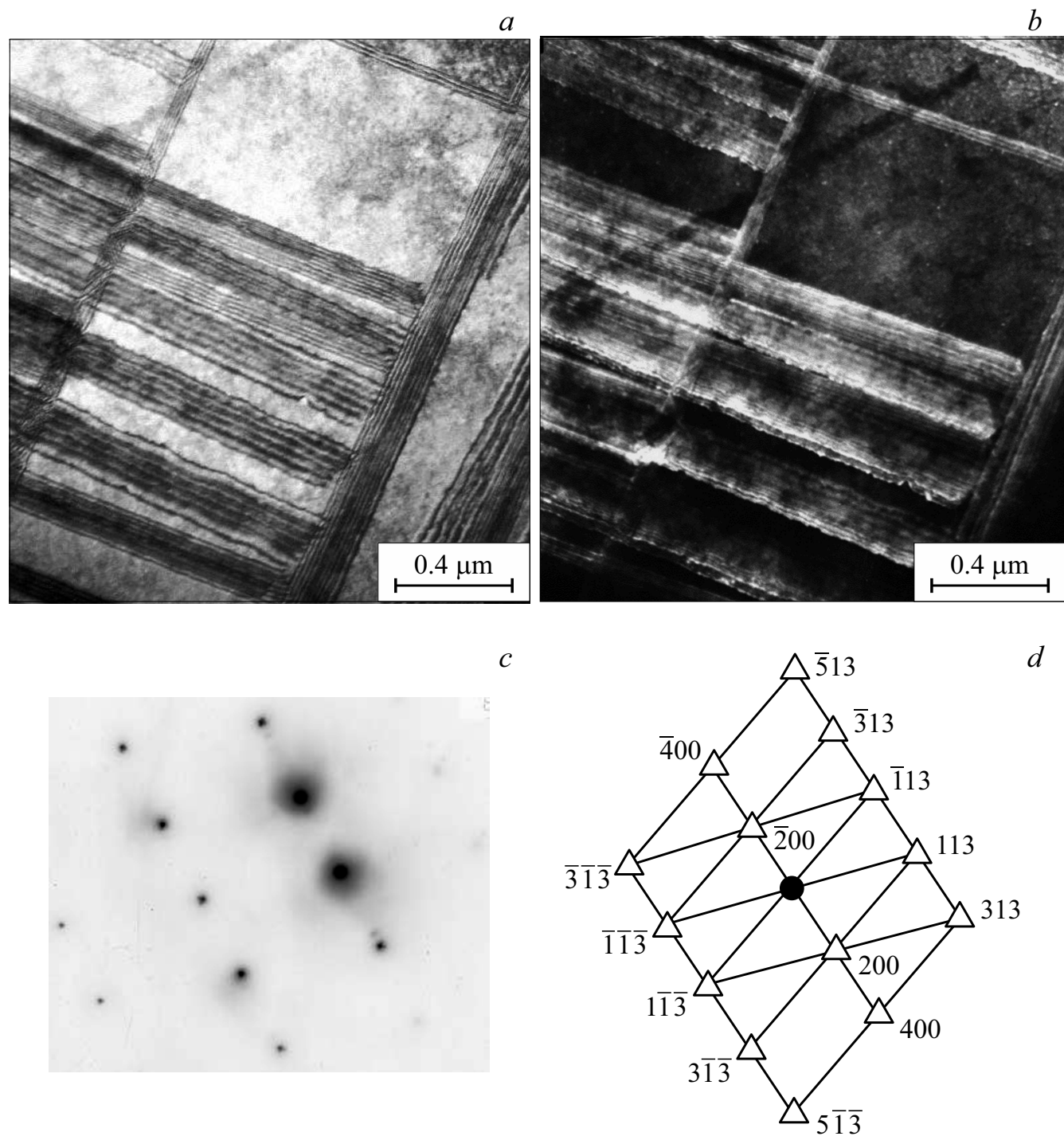

Рис. 10. Тонкая структура литого сплава Co-2wt.\% Nb: $a-$ светлопольное изображение; $b-$ темнопольное изображение в рефлексе $\overline{1} 13_{\beta} ; c$ - темнопольная электронно-дифракционная картина $\beta$-фазы, ось зоны $0 \overline{3} 1_{\beta} ; d-$ схема расшифровки электроннодифракционной картины.

\section{7. Результаты электронно-микроскопического исследования тонкой структуры сплавов Co-Nb}

При электронно-микроскопическом исследовании, как и при EBSD-анализе, старались выбирать участки структуры, не содержащие границ зерен. На плоскости фольги на рис. 10 присутствуют следы от пластин мартенсита двух разных кристаллографических ориентировок, расположенных под углом, близким к 90. На темнопольных изображениях в мартенситных рефлексах в отражающем положении находятся пластины только одной из кристаллографических ориентаций мартенсита, а именно той, которой принадлежит выбранный рефлекс. На темнопольных изображениях, полученных в рефлексах одной из ориентировок $\alpha$-фазы, в отражающем положении находятся только однонаправленные кристаллы мартенсита, в то время как на темнопольном изображении в рефлексе $113_{\beta}$ на рис. $10, b$ светятся прослойки $\beta$-фазы между пластинками мартенсита разных кристаллографических ориентаций.

На электронно-дифракционных картинах часто наблюдали совпадение рефлексов и направлений $\alpha$ - и $\beta$-фаз, свидетельствующих о выполнении ориентационных соотношений Вассермана, в частности, $[200]_{\beta}$ и $[2 \overline{1} \overline{1} 2]_{\alpha}$, $[4 \overline{2} 0]_{\beta}$ и $[3 \overline{1} \overline{2} 1]_{\alpha},[13 \overline{1}]_{\beta}$ и $[\overline{1} 2 \overline{1} 2]_{\alpha}$.

Рефлексов, относящихся к длиннопериодным мартенситным фазам типа $N R$, при электронно-дифракционном анализе обнаружено не было.

\section{4. Выводы}

1.Исследованные сплавы Co-Nb выше температуры $\beta \rightarrow \alpha$-полиморфного превращения представляли собой 
крупнозернистые поликристаллы. При полиморфном превращении, происходящем при постепенном охлаждении закристаллизовавшегося слитка, в каждом $\beta$-зерне сплава происходит зарождение кристаллов $\alpha$-фазы нескольких ориентаций из 4 возможных в соответствии с ориентационными соотношениями Вассермана. В произвольное сечение слитка сплава могут попадать не все реализовавшиеся ориентации мартенсита. При комнатной температуре в структуре исследованных сплавов обнаружен только $\alpha($ ПУ)-мартенсит. Каких-либо фаз с многослойными решетками типа $N R$-мартенсита не выявлено.

2.В структуре обоих сплавов при комнатной температуре сохраняется некоторое количество непревращенной $\beta$-фазы, растущее с увеличением содержания легирующего элемента. По данным электронномикроскопического исследования, в структуре литых сплавов присутствуют как массивные участки непревращенной $\beta$-фазы, так и тонкие ее прослойки между пластинами мартенсита.

3. С использованием метода EBSD-анализа показано, что разориентация субструктуры по длине мартенситных кристаллов в литых сплавах не превышает $1 \mathrm{deg}$.

4.После гомогенизации и последующей закалки в соленой воде структура сплавов $\mathrm{Co}-\mathrm{Nb}$ не претерпевает морфологических и кристаллографических изменений, но заметно измельчается. При этом в несколько раз возрастает разориентация элементов субструктуры по длине мартенситных кристаллов, что является следствием высокого уровня закалочных микронапряжений в мартенсите.

\section{Благодарности}

Структурные исследования на микроскопах FEI „Quanta-200“ и JEM-200CX выполнены в отделе электронной микроскопии ЦКП „Испытательный центр нанотехнологий и перспективных материалов“ Института физики металлов УрО РАН.

\section{Финансирование работы}

Работа выполнена в рамках государственного задания по теме „Структура“ (№ г.p. АААА-А18-1180201901166) при частичной финансовой поддержке Комплексной программы УрО РАН № 18-10-2-39.

\section{Конфликт интересов}

Авторы заявляют, что у них нет конфликта интересов.

\section{Список литературы}

[1] Cardellinia F., Mazzonea G. // Phil. Mag. A. 1993. Vol. 67. N 6. P. $1289-1300$.

[2] Okamoto H. // J. Phase Equilibria. 2000. Vol. 21. N 5. P. 495-496.
[3] Николин Б.И. Многослойные структуры и политипизм в металлических сплавах. Киев: Наукова думка, 1984. 240 с.

[4] Liu Y., Tan G., Miyazaki S., etal. // J. Phys. IV France. 2003. Vol. 112. P. 1025-1028.

[5] Bray D.W., Howe J.M. // Metal. Mater. Trans. A. 1996. Vol. 27A. N 11. P. 3362-3370.

[6] Wassermann G. // Metallwirtschaft. 1932. Vol. 11. N 2. S. $61-70$.

[7] Okamoto H. // J. Phase Equilibria. 2010. Vol. 31. N 1. P. 94-95.

[8] Stein F., Jiang D., Palm M., Sauthoff G., Grüner D., Kreiner G. // Intermetallics. 2008. Vol. 16. P. 785.

[9] Кокорин В.В., Ткаченко О.В., Чуистов К.В. // ФММ. 1970. т. 30. Вып. 1. С. 69-75.

[10] Николин Б.И., Шевченко Н.Н., Добровольская Т.Л. // ДАН CCCP. 1981. Т. 267. № 6. С. 1354-1357.

[11] Николин Б.И., Шевченко Н.Н., Добровольская Т.Л. // Металлофизика. 1983. Т. 5. № 5. С. 35-43.

[12] Николин Б.И., Шевченко Н.Н. // ФММ. 1981. Т. 51. Вып. 2. С. 316-325.

[13] Хлебникова Ю.В., Родионов Д.П., Сазонова В.А., Табатчикова Т.И., Антонова О.В., Турхан Ю.Э., Казанцев В.А. // ФММ. 2007. Т. 103. № 6. С. 642-651.

[14] Хлебникова Ю.В., Табатчикова Т.И., Родионов Д.П., Сазонова В.А., Казанщев В.А. // ФММ. 2009. Т. 108. № 3. C. 293-305.

[15] Мирзаев Д.А., Счастливцев В.М., Ульянов В.Г., Карзунов С.Е., Яковлева И.Л., Хлебникова Ю.В., Окишев К.Ю. // ФММ. 2002. Т. 93. № 6. С. 58-64. 